\title{
Focused antenatal care utilization and associated factors in Debre Tabor Town, northwest Ethiopia, 2017
}

Teshager Workneh Ayalew ${ }^{1}$ and Araya Mesfin Nigatu²*

\begin{abstract}
Objective: Attending antenatal care helps to reduce the occurrence of maternal morbidity and mortality by providing chances for health promotion and information about danger signs, birth preparedness and where to seek care for pregnancy complications. Therefore identifying factors affecting the utilization of focused ANC service is of supreme importance.

Results: A total of 317 mothers who had a history of antenatal care for their last birth during the previous 6 months were included in the study from which $112(35.3 \%, 95 \% \mathrm{Cl} 30.6,40.4)$ of mothers attended focused antenatal care services. Age of mother [AOR $=4.7,95 \% \mathrm{Cl} 1.87,11.88]$, Educational status [AOR $=2.5,95 \% \mathrm{Cl} 1.00,6.19]$, history of still birth $[\mathrm{AOR}=13.1,95 \% \mathrm{Cl} 2.14,80.20]$ and planned pregnancy $[\mathrm{AOR}=3.7,95 \% \mathrm{Cl} 1.23,11.12]$ were found to be major predictors for focused ANC service utilization. Proportion of focused antenatal care was low (35.3\%). Age of mother, education, history of stillbirth and planned pregnancy were identified as predictors affecting focused antenatal care service utilization. Encouraging women's educational status, behavioral change communication at grass root level and improving the capacity and quality of ANC service are some of the recommendations forwarded.
\end{abstract}

Keywords: Focused antenatal care, Mothers, Debre Tabor, Ethiopia

\section{Introduction}

According to World Health Organization WHO 2015 report, globally 303,000 maternal deaths occurred as result of pregnancy and childbirth-related complications each year with $99 \%(302,000)$ of them occurred in developing regions, sub-Saharan Africa alone accounts for roughly $66 \%(201,000)$, followed by Southern Asia $(66,000)[1]$.

It is known that ANC helps to reduce the occurrence of maternal morbidity and mortality by providing chances for health promotion and information about danger signs, birth preparedness and where to seek care for pregnancy complications [2].

Proper care during pregnancy is important as pregnancy is a crucial time for the health status of the mother

\footnotetext{
*Correspondence: hitdt2005@gmail.com

2 Department of Health Informatics, Institute of Public Health, University of Gondar, P.O.Box 196, Gondar, Ethiopia

Full list of author information is available at the end of the article
}

and the development of the unborn baby directly by reducing stillbirths and neonatal deaths [3]. Maternal mortality during pregnancy or within 42 days of termination of pregnancy, remains distressingly high in subSaharan Africa [4].

WHO recommended that a woman without complications should have at least four antenatal care visits, the first of which should take place during the first trimester [5]. Focused antenatal care (FANC) is personalized care provided to a pregnant woman which emphasizes on the women's overall health status, her preparation for child birth and readiness for complications or it is timely, friendly, simple safe services to pregnant women [2].

In Africa, the proportion of pregnant women who attended the recommended four or more visits showed remarkable change from time to time [3]; for this education played a major role [6]. As pointed out in EDHS 2014 and EDHS 2016 report same proportion (32\%) of mothers received four and above ANC visits [6,7], but remarkable increment from EDHS 2011 report 19\% [8]. 
Even though, ANC utilization in Ethiopia is very low as compared to developed and most of developing countries, little is known about the proportion and its determinant factors of FANC service utilization. So, the study intends to show current information about the prevalence of FANC and its associated factors in Debre Tabor Town.

\section{Main text \\ Methods}

A community based cross-sectional study that assessed the focused antenatal care and associated factors among mothers who gave birth 6 months before the study period in Debre Tabor Town, Amhara Regional State, northwest Ethiopia. The study was conducted between March to June 2017.

The sample size was determined using a single population proportion formula with the assumption; 95\% confidence interval, $5 \%$ margin of error, $10 \%$ estimated non-response rate and taking $25.7 \%$ proportion of focused antenatal care service use [9] then, the required sample size was 323 .

As there are urban and semi-rural kebeles in the town administration, stratified sampling technique was employed to select study subjects. Women who gave birth for the previous 6 months were participated. Heath extension workers registration book was used as a sampling frame to obtain study participants. All women who gave birth for the previous 6 months prior to the study were registered and then sample was allocated to each Kebele by proportional allocation to their population size. Finally 323 study participants were selected.

Structured and pretested interviewer administered questionnaire including socio-demographic, accessibility, behavioral and obstetrics factors variables ware used. The questionnaire was first prepared in English and then translated into Amharic version for appropriateness in approaching the study participants and then translated back to English by language experts to check its consistency. Three trained diploma nurses and one health officer was assigned as data collectors and supervisor respectively. Training was given for 2 days about the objective, relevance of the study and confidentiality issues.

Data were entered, edited and cleaned using Epi-info version 7 and exported to SPSS version 20 for further statistical analysis. The descriptive analysis such as proportions, percentages, frequency distribution and measure of central tendency were carried out.

Initially, bivariable analysis was performed between dependent and independent variables one by one. Variables found to have an association with the dependent variable less than $0.2 \mathrm{p}$-value were entered into multivariable binary logistic regression using backward LR method for controlling the possible effects of confounders. Finally the variables which had significant association were identified on the bases of odds ratio with 95\% CI. Goodness of fit test was also checked.

Focused ANC utilization is to mean that those pregnant women who attended a minimum of four scheduled ANC visits and receiving all the WHO recommended comprehensive packages by skilled healthcare providers.

Ethical clearance was obtained from the ethical review committee of Fkede Egzee College and permission was also obtained from Debre Tabor Town health office. Study participants were informed about the benefits and risks of the study. Individual participant records were coded on each respective questionnaire and accessed only by the research team members to keep confidentiality.

Training was given for data collectors and supervisor on the objective of the study, data collection procedures, data collecting tools, respondents approach, data confidentiality and respondent's right prior to the data collection date. The completeness of the questionnaire was checked every other day by the supervisors and principal investigator.

\section{Results}

In this study, a total of 317 women who gave birth 6 months before the study period were participated and responded to the questionnaire, giving a response rate of 98.1\%. One hundred twenty-six (39.7\%) were in the age group 25-29 years with mean age of 28.2 ( $\mathrm{SD} \pm 5.3$ years). Majority (94.3\%) of respondents were married. In addition, $121(38.2 \%)$ were having educational status of diploma and above and slightly more than half (56.8\%) of them were also government employee (Table 1).

The mean age at first pregnancy was $21( \pm 3.37 \mathrm{SD})$ years. About one hundred three (32.5\%) of the mothers became pregnant before the age of 20 years and 154 (48.6\%) were between the age 20-24. One hundred sixtytwo $(51.1 \%)$ of the mothers had history of two to four pregnancies and 21 (6.6\%) of them had history of more than five pregnancies. More than half of the respondents (52.7\%) had had 2-4 children and $266(83.9 \%)$ of the mothers had planned pregnancy. In addition, 10 (3.2\%) and $12(3.8 \%)$ of the mothers had a history of stillbirth and abortion respectively (Table 2 ).

Two hundred thirty-five (74.1\%) of the respondents obtained information regarding ANC from health institutions and 268 (84.5\%) knew attending ANC has the benefit for both the mother and their child. Even though 187 (57.4\%) went ANC clinic for regular checkups only 130 (41.0\%) of them had knowledge on danger sign during pregnancy (Additional file 1: Table S1). Among mothers who attended ANC for their last pregnancy, $112(35.3 \%)$ visited four and above times. At least one 
Table 1 Socio-demographic characteristics of women in Debre Tabor Town northwest Ethiopia, June, 2017 ( $n=317$ )

\begin{tabular}{|c|c|c|c|}
\hline Variable & Category & Frequency & Percent \\
\hline \multirow[t]{4}{*}{ Age of mother in years } & $\leq 24$ & 69 & 21.8 \\
\hline & $25-29$ & 126 & 39.7 \\
\hline & $30-34$ & 62 & 19.6 \\
\hline & $\geq 35$ & 60 & 18.9 \\
\hline \multirow[t]{3}{*}{ Marital status } & Single & 3 & 1.0 \\
\hline & Married & 299 & 94.3 \\
\hline & Divorced & 15 & 4.7 \\
\hline \multirow[t]{3}{*}{ Religion } & Orthodox & 294 & 92.7 \\
\hline & Muslim & 18 & 5.7 \\
\hline & Protestant & 5 & 1.6 \\
\hline \multirow[t]{5}{*}{ Educational status of the respondent } & Unable to read and write & 52 & 16.4 \\
\hline & Able to read and write & 56 & 17.7 \\
\hline & Primary education (1-8) & 18 & 5.7 \\
\hline & Secondary education (9-12) & 70 & 22.1 \\
\hline & Diploma and above & 121 & 38.2 \\
\hline \multirow[t]{6}{*}{ Occupational status of the respondent } & Government employee & 108 & 34.1 \\
\hline & Private worker & 10 & 3.2 \\
\hline & Merchant & 37 & 11.7 \\
\hline & House wife & 138 & 43.5 \\
\hline & Student & 20 & 6.3 \\
\hline & Daily laborer & 4 & 1.3 \\
\hline \multirow[t]{3}{*}{ Ethnicity } & Amhara & 312 & 98.5 \\
\hline & Oromo & 3 & 0.9 \\
\hline & Tigrian & 2 & 0.6 \\
\hline \multirow[t]{5}{*}{ Educational status of husband $(n=299)$} & Unable to read and write & 17 & 5.7 \\
\hline & Able to read and write & 55 & 18.4 \\
\hline & Primary education (1-8) & 29 & 9.7 \\
\hline & Secondary education (9-12) & 31 & 10.4 \\
\hline & Diploma and above & 167 & 55.9 \\
\hline \multirow[t]{5}{*}{ Occupational status of husband $(n=299)$} & Government employee & 162 & 54.2 \\
\hline & Private worker & 18 & 6.0 \\
\hline & Merchant & 102 & 34.1 \\
\hline & Student & 1 & 0.3 \\
\hline & Daily laborer & 16 & 5.4 \\
\hline \multirow[t]{3}{*}{ Family size } & $1-3$ & 139 & 43.8 \\
\hline & $4-6$ & 167 & 52.7 \\
\hline & $7-10$ & 11 & 3.5 \\
\hline
\end{tabular}

injection of tetanus toxoid $223(70.3 \%)$ was reported by the majority of mothers during their last pregnancy. Two hundred fifty-six (80.8\%) of the women obtained laboratory examination. Among mothers who attended ANC, $237(74.8 \%)$ of them waste their time by waiting more than $1 \mathrm{~h}$ to get the service. With regard to accessibility, majority $294(92.7 \%)$ of them had better transportation access (Additional file 1: Table S2).

In this study, 112 (35.3\%) mothers reported four and above ANC visits as per WHO recommendations
(Additional file 2: Figure S1). Regarding their reasons for to attend FANC; health worker's advice accounts the higher percentage (34.9\%) while felt discomfort accounts the least (8.6\%) (Additional file 3: Figure S2).

Age of mother, education, history of still birth and planned pregnancy were major predictors for FANC. Multivariable analysis revealed that mothers with age $\geq 35$ years $(\mathrm{AOR}=4.7,95 \% \mathrm{CI} 4.87,11.88)$ were five times more likely to attend focused antenatal care than with the age group $\leq 24$ years. Those respondents who 
Table 2 Obstetric characteristics of women in Debre Tabor Town northwest Ethiopia, June, 2017

\begin{tabular}{llll}
\hline Variables (n=317) & Category & $\begin{array}{l}\text { FANC } \\
\text { N (\%) }\end{array}$ & $\begin{array}{l}\text { Not FANC } \\
\text { N (\%) }\end{array}$ \\
\hline Age of mother at first marriage & $<15$ & $3(13.6)$ & $19(86.4)$ \\
& $15-19$ & $31(38.3)$ & $50(61.7)$ \\
& $20-24$ & $48(32.4)$ & $100(67.4)$ \\
& $25-29$ & $30(45.5)$ & $36(54.5)$ \\
Age of mother at first pregnancy & $<20$ & $34(33.0)$ & $69(67.0)$ \\
Gravidity & $\geq 20$ & $78(36.4)$ & $136(63.6)$ \\
& 1 & $40(29.9)$ & $94(70.1)$ \\
Parity & $2-4$ & $67(41.4)$ & $95(58.6)$ \\
& $\geq 5$ & $5(23.8)$ & $16(76.2)$ \\
History of abortion & 1 & $40(28.8)$ & $99(71.2)$ \\
& $2-4$ & $68(41.2)$ & $97(58.8)$ \\
History of still birth & $\geq 5$ & $4(30.8)$ & $9(69.2)$ \\
& Yes & $8(66.7)$ & $4(33.3)$ \\
Planned pregnancy & No & $104(34.1)$ & $201(98)$ \\
& Yes & $7(6.3)$ & $3(1.5)$ \\
& No & $105(93.7)$ & $202(65.9)$ \\
& Yes & $105(39.5)$ & $161(60.5)$ \\
& No & $7(13.2)$ & $44(86.85)$ \\
\hline
\end{tabular}

had diploma and above educational status $(\mathrm{AOR}=2.5$, $95 \%$ CI $1.00,6.19$ ) were three times more likely to attend focused antenatal care when compared to mothers who didn't read and write. Respondents who had history of still birth (AOR $=13.1,95 \%$ CI 2.14, 80.20) were 13 times more likely to attend focused antenatal care than who didn't encounter in their life time. Mothers having planned pregnancy $(\mathrm{AOR}=3.7,95 \% \mathrm{CI} 1.23,11.12)$ were four times more like to utilize focused antenatal care service compared to those who didn't plan (Table 3).

\section{Discussion}

According to WHO recommendation, women should receive four and above ANC visits for normal pregnancy [3]. The finding of this study revealed that $35.3 \%$ (95\% CI $30.6 \%, 40.4 \%)$ of mothers attended FANC service. This finding was consistent with EDHS 2011 report on Amhara Region 34\% [8] and Kenya 32\% [9], but was higher than previous studies done in Ethiopia districts like East Wolega 14.4\% [10], Dejen and Aneded 12\% [11] and abroad Kenya 27\% [12]. The difference might be due to cultural and awareness differences and currently the government of Ethiopia has given attention by making the service as one of the exempted services.

This finding appeared to be lower than studies done in Ethiopia (Eastern Hararghe zone 38.3\% [13] and Holeta town 66\% [14]) and abroad Kenya 52\% [15], Nigeria $81.5 \%$ [16] and Nepal 87\% [17]. The probable reason for this might be due to availability of private quality service providing health facilities and also availability of approachable healthcare providers.

In this study mothers whose age $\geq 35$ years $(\mathrm{AOR}=4.7$, $95 \%$ CI $4.87,11.88$ ) were five times more likely to attend FANC service than mother having age group $\leq 24$ years. This finding was supported by study done in Wonberma Woreda (Ethiopia) [18] and abroad Nigeria [16]. This might be due to as the age of the mother's increases, they might have a better knowledge, understanding and experience of pregnancy and pregnancy related complications.

The result of this study also showed that mothers who attended diploma education and above $(\mathrm{AOR}=2.5,95 \%$ CI $1.00,6.19)$ were three times more likely to attend FANC than those who were unable to read and write. Previous studies done in developing countries have been found that higher educational level was highly associated with much better antenatal care service utilization $[8,16,19,20]$. The probable reason for this might be due to; women having better educational status are capable of identifying danger signs and easily understand the bad consequence of not attending the recommended antenatal care service.

Highly statistical significant association was also obtained between history of still birth and focused antenatal care service utilization. Mothers who experienced stillbirth before recent pregnancy $(\mathrm{AOR}=13.1,95 \% \mathrm{CI}$ $2.14,80.20$ ) were 13 times more likely to utilize antenatal care than those didn't encountered any yet. This finding was in line with a study done in Ethiopia [19]. The possible explanation for this might be because of those who faced still birth knew the risks associated with it; as a result they might utilize focused antenatal care in order to prevent it and have good pregnancy outcome.

This finding also revealed that planned pregnancy was found to be significantly associated with the utilization of FANC. Pregnant women whose have planned pregnancy $(\mathrm{AOR}=3.7,95 \%$ CI 1.23, 11.12) were four times more likely to use focused antenatal care service when compared to those having unplanned pregnancy. This finding is consistent with studies done elsewhere [18, 21]. The possible justification for this might be due to the fact that mother who plan to have a child might want to have a healthy pregnancy and thus might give a great attention for their antenatal care service.

In conclusion, this study proportion was low (35.3\%) and $41 \%$ had knowledge about danger signs during pregnancy. Age, women's educational status, history of still birth and planned pregnancy were found to be fundamental predictors of focused antenatal care service utilization. It is well documented that antenatal care visits has the potential in reducing maternal pregnancy related 
Table 3 Bivariable and multivariable analysis of focused ANC in Debre Tabor Town, northwest Ethiopia, June, 2017 $(\mathrm{n}=317)$

\begin{tabular}{|c|c|c|c|c|}
\hline \multirow[t]{2}{*}{ Variables } & \multicolumn{2}{|l|}{ ANC } & \multirow{2}{*}{$\begin{array}{l}\text { Crude OR } \\
(95 \% \mathrm{Cl})\end{array}$} & \multirow{2}{*}{$\begin{array}{l}\text { Adjusted OR } \\
(95 \% \mathrm{Cl})\end{array}$} \\
\hline & Non focused (\%) & Focused (\%) & & \\
\hline \multicolumn{5}{|l|}{ Age mother } \\
\hline$\leq 24$ & $42(60.9)$ & $27(39.1)$ & 1.00 & 1.00 \\
\hline $25-29$ & $94(74.6)$ & $32(25.4)$ & $0.5(0.28,0.99)$ & $0.6(0.28,1.16)$ \\
\hline $30-34$ & $43(69.4)$ & 19 (30.6) & $0.7(0.33,1.42)$ & $0.6(0.27,1.42)$ \\
\hline$\geq 35$ & $26(43.3)$ & $34(56.7)$ & $2.0(1.01,4.12)$ & $4.7(1.87,11.88)^{* *}$ \\
\hline \multicolumn{5}{|c|}{ Decision of ANC service utilization } \\
\hline Husband & $25(73.5)$ & $9(26.5)$ & 1.00 & \\
\hline Wife & $74(83.1)$ & $15(16.9)$ & $0.56(0.22,1.46)$ & \\
\hline Both & $106(54.6)$ & $88(45.4)$ & $2.31(1.02,5.19)$ & \\
\hline \multicolumn{5}{|l|}{ Educational status of mother } \\
\hline Unable to read and write & $37(71.2)$ & $28(47.5)$ & 1.00 & 1.00 \\
\hline Able to read and write & $40(71.4)$ & $57(55.3)$ & $0.9(0.43,2.72)$ & $1.6(0.16,1.87)$ \\
\hline Primary school (1-8) & $15(83.3)$ & $81(53.3)$ & $0.5(0.12,1.96)$ & $0.3(0.07,1.58)$ \\
\hline Secondary school (9-12) & $49(70)$ & $3(30)$ & $1.1(0.48,2.33)$ & $1.8(0.66,4.98)$ \\
\hline Diploma and above & $64(52.9)$ & $57(47.1)$ & $2.2(1.09,4.42)$ & $2.5(1.00,6.19)^{* *}$ \\
\hline \multicolumn{5}{|l|}{ Gravidity } \\
\hline One & $94(70.1)$ & $40(29.9)$ & 1.00 & \\
\hline Two to four & 95 (58.6) & $67(41.4)$ & $1.7(1.02,2.69)$ & \\
\hline 5 and above & $16(76.2)$ & $5(23.8)$ & $2.6(0.25,2.14)$ & \\
\hline \multicolumn{5}{|l|}{ Parity } \\
\hline One & $99(71.2)$ & $40(28.8)$ & 1.00 & \\
\hline Two to four & $97(58.8)$ & $67(41.4)$ & $1.7(1.07,2.81)$ & \\
\hline 5 and above & $9(69.2)$ & $5(23.8)$ & $1.1(0.32,3.78)$ & \\
\hline \multicolumn{5}{|l|}{ Source of information for ANC } \\
\hline Health institution & $138(58.7)$ & $97(41.3)$ & $11.6(2.72,49.48)$ & \\
\hline Media/TV, radio & $15(57.7)$ & $14(42.3)$ & $12.4(2.38,61.448)$ & \\
\hline Health development army & $19(90.5)$ & $2(9.5)$ & $1.74(0.23,13.35)$ & \\
\hline Friend & $33(94.3)$ & $2(5.7)$ & 1.00 & \\
\hline \multicolumn{5}{|l|}{ History of abortion } \\
\hline Yes & $4(33.3)$ & $8(66.7)$ & $3.9(1.14,13.14)$ & \\
\hline No & $201(65.9)$ & $104(34.1)$ & 1.00 & \\
\hline \multicolumn{5}{|l|}{ History of still birth } \\
\hline Yes & $3(30)$ & $7(70)$ & $4.5(1.14,17.72)$ & $13.1(2.14,80.20)^{* *}$ \\
\hline No & $202(65.8)$ & $105(34.2)$ & 11.00 & 1.00 \\
\hline \multicolumn{5}{|l|}{ Planned pregnancy } \\
\hline Yes & $161(60.5)$ & 105 (39.5) & $4.1(1.78,9.44)$ & $3.7(1.23,11.12)^{* *}$ \\
\hline No & 44 (86.3) & $7(13.7)$ & 1.00 & 1.00 \\
\hline
\end{tabular}

$1.00=$ reference, Hosmier and Lemesho goodness of fit test $=0.81$

risks and improving newborn's health if mothers have knowledge on danger sign during pregnancy. Therefore, each pregnant mother should receive the recommended WHO antenatal care visits as it is important to identify risk factors for adverse pregnancy outcomes, both for the mother and their newborn.

\section{Limitations}

Due to the cross-sectional nature of the study, it is difficult to establish cause-effect relationship between dependent and independent variables and social desirability as it was face to face interview. 


\section{Additional files}

Additional file 1: Table S1. Antenatal care knowledge of mothers in Debre Tabor Town northwest Ethiopia, June, 2017. Table S2. ANC service utilization of mothers in Debre Tabor Town northwest Ethiopia, June, 2017.

Additional file 2: Fig. S1. Prevalence of FANC among pregnant women attending ANC in Debre Tabor Town, northwest Ethiopia June, 2017.

Additional file 3: Fig. S2. Reasons why mothers did attend ANC services in Debre Tabor Town, northwest Ethiopia June, 2017

\section{Abbreviations}

ANC: ante natal care; EDHS: Ethiopian Demographic and Health Survey; FANC: focused ante natal care; FMOH: Federal Ministry of Health; WHO: World Health Organization.

\section{Authors' contributions}

Both authors equally participated in the conception, design, analysis, and interpretation. TW initiated and conducted the research, analyzed, interpreted the data and prepared the draft manuscript. AM the corresponding author made critical revision on the drafted manuscript. Both authors had full access to all of the data in the study and take responsibility for the integrity of the data and the accuracy of the data analysis. Both authors read and approved the final manuscript.

\section{Author details}

1 Department of Health Information Technology, Debre Tabor Health Science College, P.O.Box 83, Debre Tabor, Amhara Regional State, Ethiopia. ${ }^{2}$ Department of Health Informatics, Institute of Public Health, University of Gondar, P.O.Box 196, Gondar, Ethiopia.

\section{Acknowledgements}

We are grateful to Fekede Egezi College for permission to conduct the study. We are also grateful for study participants and supervisors for their unreserved participation during the data collection.

\section{Competing interests}

The authors declare that they have no competing interests.

\section{Availability of data and materials}

The data is available and may be delivered upon request.

\section{Consent for publication}

As there were no images and videos related to the study participants, only informed consent was held.

\section{Ethics approval and consent to participate}

Ethical clearance was obtained from Fekede Egzi College and informed consent was done for each study participants. In addition the benefits and risks of the study were informed.

\section{Funding}

The authors disclose that did not receipt any fund for this research, and publication of this article. This research was self-sponsored.

\section{Publisher's Note}

Springer Nature remains neutral with regard to jurisdictional claims in published maps and institutional affiliations.

Received: 15 October 2018 Accepted: 12 November 2018 Published online: 16 November 2018
References

1. Bongaarts J. WHO, UNICEF, UNFPA, World Bank Group, and United Nations population division trends in maternal mortality: 1990 to 2015 Geneva: World Health Organization, 2015. Popul Dev Rev. 2016;42(4):726.

2. World HO. Mother-baby package: implementing safe motherhood in countries: practical guide. 1996.

3. Lincetto O, Mothebesoane-Anoh S, Gomez P, Munjanja S. Antenatal care. Opportunities for Africa's newborns: practical data, policy and programmatic support for newborn care in Africa. 2006. p. 55-62.

4. Getachew T, Abajobir A, Aychiluhim M. Focused antenatal care service utilization and associated factors in Dejen and Aneded Districts, Northwest Ethiopia. Prim Health Care. 2014:4(170):2167.

5. Organization WH. Mother-baby package: implementing safe motherhood in countries: practical guide. 1996.

6. Central SAAA. Ethiopia Demographic and Health Survey 2016. Key indicator report. The DHS Program. Rockville: ICF; 2016.

7. Central SAE. Ethiopia Mini Demographic and Health Survey 2014. Addis Ababa: Central Statistical Agency; 2014.

8. Demographic CE. Health survey-2011. Addis Ababa and Calverton: Central Statistical Agency, ICF International. 2012. 2016.

9. Chorongo D, Okinda FM, Kariuki EJ, Mulewa E, Ibinda F, Muhula S, et al. Factors influencing the utilization of focused antenatal care services in Malindi and Magarini sub-counties of Kilifi county, Kenya. Pan Afr Med J. 2016:25(Suppl 2):14.

10. Tekelab T, Yadecha B, Melka AS. Antenatal care and women's decision making power as determinants of institutional delivery in rural area of Western Ethiopia. BMC Res Notes. 2015;8(1):769.

11. Getachew T, Abajobir AA, Aychiluhim M. Antenatal care service utilization and associated factors in Dejen and Aneded Districts, Northwest Ethiopia. Prim Health Care. 2014;4:4.

12. Chorongo D, Okinda FM, Kariuki EJ, Mulewa E, Ibinda F, Muhula S, et al. Factors influencing the utilization of focused antenatal care services in Malindi and Magarini sub-counties of Kilifi county, Kenya. Pan Afr Med J. 2016;25(Suppl 2):14.

13. Zelalem Ayele D, Belayihun B, Teji K, Admassu Ayana D. Factors affecting utilization of maternal health Care Services in Kombolcha District, eastern Hararghe zone, Oromia regional state, eastern Ethiopia. Int Sch Res Notices. 2014;2014:7

14. Birmeta K, Dibaba Y, Woldeyohannes D. Determinants of maternal health care utilization in Holeta town, central Ethiopia. BMC Health Serv Res. 2013;13(1):256

15. Gitonga E. Determinants of focused antenatal care uptake among women in tharaka nithi county, Kenya. Adv Public Health. 2017;2017:4.

16. Fagbamigbe AF, Idemudia ES. Assessment of quality of antenatal care services in Nigeria: evidence from a population-based survey. Reprod Health. 2015;12(1):88

17. Tuladhar H, Dhakal N. Impact of antenatal care on maternal and perinatal outcome: a study at Nepal Medical College Teaching Hospital. Nepal J Obstet Gynaecol. 2011;6(2):37-43.

18. Mulat G, Kassaw T, Aychiluhim M. Antenatal care service utilization and its associated factors among mothers who gave live birth in the past one year in Womberma Woreda, North West Ethiopia. Epidemiology. 2015 https://doi.org/10.4172/2161-1165.S2-003.

19. Nebeb GT, Salgedo WB, Alemayehu YK. Antenatal care utilization in Debre Tabor, North West Ethiopia. Gynecol Obstet. 2015;5:339. https://doi. org/10.4172/2161-0932.1000339.

20. Tura G. Antenatal care service utilization and associated factors in Metekel Zone, Northwest Ethiopia. Ethiop J Health Sci. 2009. https://doi. org/10.4314/ejhs.v19i2.69415

21. Tewodros B, Dibaba Y. Factors affecting antenatal care utilization in Yem special woreda, southwestern Ethiopia. Ethiop J Health Sci. 2009:19(1):45-51. 